This is the accepted manuscript of the following article:

Perez-Calleja, P., Aybar, M., Picioreanu, C., Esteban-Garcia, A. L., Martin, K. J., \& Nerenberg, R. (2017). Periodic venting of MABR lumen allows high removal rates and high gas-transfer efficiencies. Water Research, 121:349-360.

The manuscript has been published in final form at: https://doi.org/10.1016/i.watres.2017.05.042 


\section{Periodic venting of MABR lumen allows high removal rates}

\section{2 and high gas-transfer efficiencies}

3

4 P. Perez-Calleja ${ }^{\mathrm{a}, \mathrm{b}}$, M. Aybar ${ }^{\mathrm{a}, \mathrm{c}}$, C. Picioreanu ${ }^{\mathrm{d}}$, A.L. Esteban-Garcia ${ }^{\mathrm{b}}$, K.J. Martin ${ }^{\mathrm{e}}$, 5 R. Nerenberg ${ }^{a^{*}}$

6 a University of Notre Dame, Department of Civil and Environmental Engineering and Earth

7 Sciences 156 Fitzpatrick Hall, Notre Dame, IN 46556, USA. nerenberg.1@nd.edu,

8 maybar@nd.edu, pperezca@nd.edu

$9{ }^{\mathrm{b}}$ University of Cantabria, Department of Sciences and Techniques of Water and the

Environment, University of Cantabria, Avda. Los Castros s/n, 39005 Santander, Spain. analorena.esteban@unican.es,pperezca@nd.edu

Universitaria, Concepcion, Chile. maybar@udec.c1

${ }^{\mathrm{d}}$ Department of Biotechnology, Faculty of Applied Sciences, Delft University of Technology,

Van der Maasweg 9, 2629 HZ, Delft, The Netherlands. c.picioreanu@tudelf.nl

${ }^{\mathrm{e}}$ Black and Veatch, 8400 Ward Parkway, Kansas City, Missouri 64114, USA.

MartinKJ@bv.com 


\section{ABBREVIATIONS}

27 DO - Dissolved oxygen

28 GTE - Gas transfer efficiency

29 GTR - Gas transfer rate

$30 \mathrm{~J}-$ Contaminant removal flux

31 HFM - Hollow-fiber membrane

32 MABR - Membrane-aerated biofilm reactor

33 MBfR - Membrane-biofilm reactor 


\section{$34 \quad$ ABSTRACT}

35 The membrane-aerated biofilm reactor (MABR) is a novel treatment technology that

\section{KEYWORDS} gas transfer rate employs gas-supplying membranes to deliver oxygen directly to a biofilm growing on the membrane surface. When operated with closed-end membranes, the MABR provides 100-percent oxygen transfer efficiencies (OTE), resulting in significant energy savings. However, closed-end MABRs are more sensitive to back-diffusion of inert gases, such as nitrogen. Back-diffusion reduces the average oxygen transfer rates (OTR), consequently decreasing the average contaminant removal fluxes (J). We hypothesized that venting the membrane lumen periodically would increase the OTR and J. Using an experimental flow cell and mathematical modeling, we showed that back-diffusion gas profiles developed over relatively long timescales. Thus, very short ventings could re-establish uniform gas profiles for relatively long time periods. Using modeling, we systematically explored the effect of the venting interval (time between ventings). At moderate venting intervals, opening the membrane for 20 seconds every 30 minutes, the venting significantly increased the average OTR and $\mathrm{J}$ without substantially impacting the OTEs. When the interval was short enough, in this case shorter than 20 minutes, the OTR was actually higher than for continuous open-end operation. Our results show that periodic venting is a promising strategy to combine the advantages of open-end and closed end operation, maximizing both the OTR and OTE.

Hollow-fiber membranes; MBfR; MABR; gas back-diffusion; gas transfer efficiency; 


\section{INTRODUCTION}

59 Gas-transferring, hollow-fiber membranes (HFM) are commonly used to supply gases

60 for environmental, industrial and medical applications. For example, bundles of HFMs have been used for oxygenation of rivers and water streams, for blood oxygenation, and for bioremediation of groundwater contaminants (Weiss et al., 1998; Roggy et al., 2002; Federspiel and Henchir, 2004). However, an emerging application is the membranebiofilm reactor (MBfR), where HFMs supply gaseous substrates to a biofilm growing directly on the membrane's outer surface (Martin and Nerenberg, 2012; Nerenberg, 2016). When used to deliver air or oxygen, the process is often referred to as the membrane-aerated biofilm reactor (MABR). MABRs can simultaneously remove biological oxygen demand (BOD), nitrify, and denitrify (Timberlake et al., 1988; Hibiya et al., 2003; Terada et al., 2003; Jácome et al., 2006; Matsumoto et al., 2007; Syron and Casey, 2008). Several commercial applications are in development, but very few fullscale applications exist.

MABRs can be operated with closed or open-ended HFMs. With closed-ended HFMs, all the oxygen supplied to the membranes is delivered to the biofilm, allowing $100 \%$ oxygen transfer efficiencies (OTEs) (Brindle et al., 1998; Pankhania et al., 1999; Hibiya et al., 2003; Terada et al., 2003; Syron and Casey, 2008; Martin and Nerenberg, 2012). This can save up to $85 \%$ in energy costs, compared to conventional activated sludge process (Aybar et al., 2014). However, closed-ended HFMs typically suffer from gas back-diffusion, where $\mathrm{N}_{2}$ and other dissolved gases diffuse into the membrane lumen (Schaffer et al., 1960; Ahmed and Semmens, 1992a). With back-diffusion, the distal 
With open-ended HFMs, the intra-membrane gas velocity is high throughout the membrane. With high velocities, advective mass transport in the lumen is much greater than the diffusive transfer across the membrane wall. This results in more uniform oxygen concentrations in the lumen, leading to high average OTRs (Figure 1b). However, a large amount of gas is lost from open end. Also, the high gas velocity leads to greater frictional pressure losses occurrence along the membrane, resulting in greater energy requirements and lower gas pressures at the distal end of the membrane. For the MABR, lower overall OTR translates into lower average substrate removal fluxes (J).

91

(a)

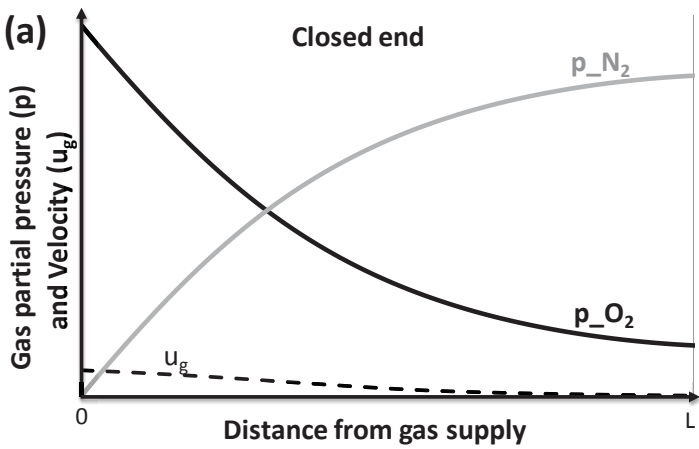

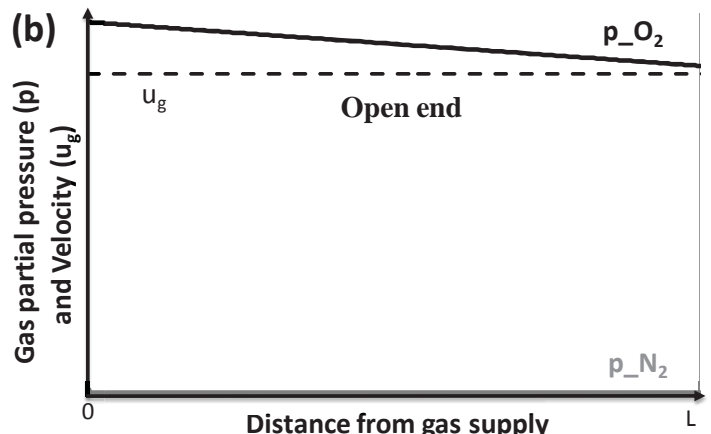

Figure 1. Schematic showing differences between hollow-fiber membranes at steady-state in: (a) closedend operation, and (b) open-end operation. In this example, the membrane is pressurized with pure $\mathrm{O}_{2}$ transferring to liquid containing dissolved $\mathrm{N}_{2}$. Figures show typical oxygen and nitrogen partial pressures $\left(p_{O 2}\right.$ and $\left.p_{N 2}\right)$ and gas velocities $\left(u_{g}\right)$ along the membrane length. The open end membrane has higher $p_{O 2}$ across the entire membrane, leading to higher gas transfer rates, but has low gas transfer efficiencies, as most of the gas is vented through the end.

Many researchers have explored ways to improve the OTR of HFMs (Weissman and Mockros, 1969; Tanishita et al., 1978; Côte et al., 1989; Ahmed and Semmens, 1992b; Matsuda et al., 1999; Ahmed et al., 2004). However, few studies have tried to 
concurrently improve the OTR and OTE. A novel approach may be periodically opening the membranes to vent back-diffusion gases. This will allow the back-diffusion gases to be vented to the atmosphere during the open phase, re-establishing the uniform almost constant gas pressure profile along the fiber length.

Previous research experimentally explored increasing the gas flow rates, or intermittent degassing processes (Li et al., 2010; Castagna et al., 2015). Fang et al., (2004) measured and modeled the gas composition inside a membrane, and gave modeled predictions of gas concentration profiles as a function of time applying when supplied with a pulsing strategy. However, they did not systematically explore the impacts of the pulsing frequency on the OTE and OTR, and their model was only applicable under conditions of liquid creeping flow.

The objective of this study was to use experiments and modeling to systematically explore periodic venting of hollow-fiber membranes as a means to maximize the OTE and OTR of MABRs.

\section{MATERIALS AND METHODS}

Our strategy was to (1) experimentally study OTRs and OTEs for "clean" HFMs (i.e., without biofilm), for open end, closed end, and for periodic venting, (2) use mathematical modeling to expand the experimental findings and predict the effects of periodic venting for a clean HFM, and (3) experimentally assess the periodic venting strategy for an MABR (i.e., a HFM with biofilm). OTR was calculated as the oxygen flux difference between the inlet and the outlet which corresponds to the flux of oxygen transferred across the membrane surface. OTE was calculated as the flux difference 
126 divided by the inlet flux. OTE represents the percentage of the transferred oxygen flux with respect to the supplied oxygen. Fluxes were estimated according to equation (1).

\subsection{Experimental flow cells configuration}

An experimental flow cell with a single HFM was used to explore OTRs and gas back diffusion in clean HFMs, i.e., without biofilm. The flow cell consisted of square-section glass tube with 6-mm inside dimension, and 40-cm length. The flow cell had seven ports for dissolved oxygen (DO) measurements (Figure 2), separated $3.8 \mathrm{~cm}$ along the flow cell. Water was deoxygenated by nitrogen sparging and pumped through the flow cell using a peristaltic pump (Cole Palmer, Vernon Hills, IL, USA).

Tests were first carried out to determine the HFM's mass transfer coefficient. To test the mathematical model, experiments were then performed with a range of water velocities, oxygen supply pressures, feed gases (air and pure oxygen), water flow directions (co-current or counter current with respect to the inlet gas supply), and transient shifts between open and closed ends.

The flow cell used a composite, microporous polyethylene membrane with a dense 1 $\mu \mathrm{m}$ polyurethane core (HFM200TL, Mitsubishi Rayon, Japan). The outer diameter was $280-\mu \mathrm{m}$ and the wall thickness was $40-\mu \mathrm{m}$. A single membrane was located in the middle of the flow cell, supported at both ends by a gas-supplying manifold. The gas was supplied from one end at constant pressure, while a valve at the opposite end allowed open or closed operation of the membrane. Pure oxygen or air was supplied at 1470.07 or 0.18 atm relative pressure. The influent flow rate ranged from 2 to $10 \mathrm{~mL} / \mathrm{min}$, resulting in a liquid velocity of 1 to $5 \mathrm{~mm} / \mathrm{s}$ and a Reynolds number of 5 to 28 , well within the laminar flow regime. 
(a)

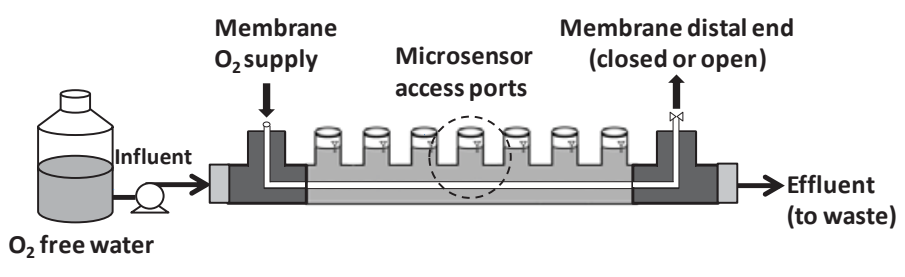

150 (b)

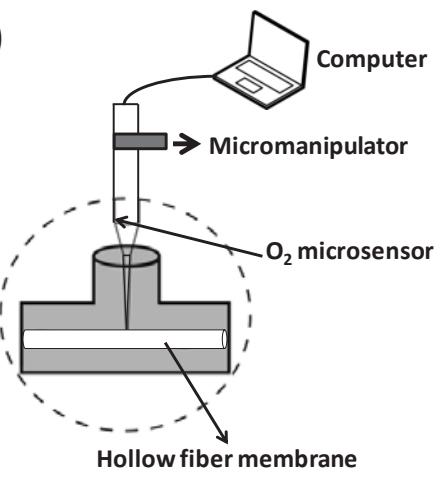

Figure 2. (a) Schematic of flow cell. Oxygen-free water from a reservoir was pumped into the squaresection glass tube with a hollow-fiber membrane supplied with $\mathrm{O}_{2}$ or air in the middle. (b) Detail of a flow-cell port used for DO measurement with a microsensor controlled by a micromanipulator.

Two separate reactors were used for the MABR tests, with the same configuration as described above. Reactor MABR-1 was operated with an open-ended membrane, while MABR-2 was initially operated with a closed end, but later was operated with periodic opening to vent lumen gases. De-oxygenated synthetic media (described below) was pumped through the flow cell. Each MABR had a recirculation pump and was connected to a purging reservoir, where the bulk liquid was sparged with $\mathrm{N}_{2}$ to strip any residual DO from the reactor. Bulk liquid $\mathrm{N}_{2}$ bubbles were vented in the reservoir before recycle line back to the flow-cell. This avoided any DO accumulation in the bulk liquid, which was a concern in the initial stages, prior to biofilm development. A magnetic stir bar kept the reservoir well-mixed with a high shear velocity, minimizing the attachment of biomass to the glass surface. An influent flow rate of $1 \mathrm{~mL} / \mathrm{min}$ and a recirculation of $60 \mathrm{~mL} / \mathrm{min}$ were provided to each MABR. Pure oxygen was supplied to the lumen of each at $0.05 \mathrm{~atm}$ relative pressure. 


\subsection{Synthetic medium for the MABRs}

171 The synthetic wastewater for MABR-1 and MABR-2, was prepared from distilled water amended with $2.773 \mathrm{~g} \mathrm{Na}_{2} \mathrm{HPO}_{4}, 0.169 \mathrm{~g} \mathrm{KH}_{2} \mathrm{PO}_{4}, 0.410 \mathrm{~g} \mathrm{MgSO}_{4} .7 \mathrm{H}_{2} \mathrm{O}$ and 0.202 $\mathrm{g}\left(\mathrm{NH}_{4}\right)_{2} \mathrm{SO}_{4}$ per liter, as well as a trace mineral and calcium iron solutions. $\mathrm{Ca}-\mathrm{Fe}$ solution contained, per liter: $1 \mathrm{~g} \mathrm{CaCl}_{2}-2 \mathrm{H}_{2} \mathrm{O}$ and $1 \mathrm{gFeSO}_{4}-7 \mathrm{H}_{2} \mathrm{O}$. The trace mineral solution contained, per liter: $100 \mathrm{mg} \mathrm{ZnSO}_{4}-7 \mathrm{H}_{2} \mathrm{O}, 30 \mathrm{mg} \mathrm{MnCl}_{2}-\mathrm{H}_{2} \mathrm{O}, 300 \mathrm{mg}$ $\mathrm{H}_{3} \mathrm{BO}_{3}, 200 \mathrm{mg} \mathrm{CoCl}_{2}-6 \mathrm{H}_{2} \mathrm{O}, 10 \mathrm{mg} \mathrm{CuCl}_{2}-2 \mathrm{H}_{2} \mathrm{O}, 10 \mathrm{mg} \mathrm{NiCl}_{2}-6 \mathrm{H}_{2} \mathrm{O}, 30 \mathrm{mg}$ $\mathrm{Na}_{2} \mathrm{MoO}_{4}-2 \mathrm{H}_{2} \mathrm{O}$, and $30 \mathrm{mg} \mathrm{Na} \mathrm{SeO}_{3}$. Potassium acetate was added as a COD source to achieve $30 \mathrm{mgCOD} / \mathrm{L}$. The synthetic wastewater was maintained anoxic by sparging the medium with nitrogen gas and maintaining a positive pressure of nitrogen gas on the storage container. The $\mathrm{pH}$ was maintained at approximately 7 , while the water temperature was $22^{\circ} \mathrm{C}$.

\subsection{Analytical methods}

Chemical oxygen demand (COD) was monitored in the influent and effluent of the MABR reactors using colorimetric methods (Hach, Loveland, CO, USA). A glass electrode $\mathrm{pH}$ meter was used to monitor $\mathrm{pH}$.

For determining the biofilm thickness, we used a stereo-zoom light microscope (ColePalmer, Chicago, IL) equipped with a mounted digital camera (Cybershot DSC-F707, Sony) and a fiber-optic light source. The camera was fixed to the microscope with a $1 \times$ mounting adapter. Biofilm thicknesses were measured using a microsensor by attaching 190 it to a motorized micromanipulator with a vertical resolution of $0.010 \mathrm{~mm}$. The microsensor tip was first positioned at membrane surface. Then, the tip was raised with the computer-controlled motor until the tip reached the outer edge of the biofilm, which was checked visually by microscopy. The distance was measured and recorded by 
SensorTrace Suit software (Unisense). Biofilm image acquisition was also performed in all seven flow-cell ports after four weeks of operation. Image processing for each measurement was followed by statistical evaluation of the results.

\subsection{DO measurements}

Clark-type oxygen microsensors (Unisense A/S, Denmark) with a $10 \mu \mathrm{m}$ tip diameter were used to measure DO concentrations. The microelectrode movement was controlled with a micro-manipulator (Model MM33-2, Unisense A/S). The use of microsensors is an invasive method that can slightly affect the results. However, considering that the tip was only $10 \mu \mathrm{m}$ diameter and was immersed in a much thicker boundary layer, the microsensors would be expected to have a minimal impact on the DO concentration. Hydrodynamic measurements made by Hondzo et al., (2005), using a similar DO microsensor diameters and Reynolds number as used in this study, concluded that the disturbance of the flow by microsenors stem was minimal.

Longitudinal profiles of DO at the HFM surface were collected from the seven ports once the system reached steady state, typically after two hours. For each port, transversal DO profiles were collected starting from the HFM surface, across the liquid diffusion layer (LDL), and into the bulk. The transversal DO measurements were collected at $20-\mu \mathrm{m}$ intervals, typically reached a distance of around $1000 \mu \mathrm{m}$ from the membrane surface. Profiles were collected at least in triplicate. For transient conditions, DO was measured continuously at the membrane surface, for one of the intermediate ports, during the shift from open-end to closed-end operation. Longitudinal steady-state DO profiles were also taken in both MABRs after four weeks of operation.

\subsection{Calculation of membrane mass transfer coefficient, $K_{m}$}


219 The membrane mass transfer coefficient, $K_{m}$, was calculated from oxygen transfer tests

220 in clean membranes. We used measured transversal DO profiles in the diffusion-

221 dominated liquid boundary layer, using the flux continuity condition. The oxygen flux

222 across the HFM, $J_{O 2, m}$, is equal to the diffusion flux through the mass transfer boundary

223 layer at the membrane surface, $J_{O 2, l}$, as follows:

224

$$
J_{O 2, m}=K_{m}\left(C_{O 2, m(g)}-C_{O 2, m(l)}\right)=\left.D_{O 2, l} \frac{d C_{O 2, l}}{d r}\right|_{r=R_{m}}=J_{O 2, l}
$$

where $D_{O 2, l}$ is the diffusion coefficient in the liquid phase (water), $C_{O 2, l}$ is the measured oxygen concentration in water, $C_{O 2, m}$ is the oxygen concentration in the microporous membrane on (g) gas side and (1) liquid side, and $R_{m}$ the outer radius of the membrane. Given the small membrane thickness relative to the HFM radius, the membrane was approximated as a planar surface. From eq. (1) the oxygen mass transfer coefficient in the membrane is calculated as:

$$
K_{m}=\frac{D_{O 2, l}\left(d C_{O 2, l} / d r\right)_{r=R m}}{C_{O 2, m(g)}-C_{O 2, m(l)}}
$$

The oxygen diffusivity in water $D_{O 2, l}$ was obtained from the literature (Haynes et al., 2015). The oxygen concentration in the gas side of the microporous membrane, $C_{O 2, m(g) \text {, }}$ is linked, by the ideal gas law, to the applied pressure and gas composition $y_{O 2}$ (either $\mathrm{O}_{2}$ or air, at the working temperature). When determining the $K_{m}$, the HFM was operated in open end mode to minimize concentration changes. Also, microsensor measurements were carried out at the first port of the flow cell (from the left side), where the gas concentration was essentially equal to the supply concentration, $C_{O 2, m(g)}=p y_{O 2, i n} /(R T)$. The oxygen gas concentration in the membrane, where it contacts the liquid, is related to the DO concentration in the liquid by the partition 
equilibrium (Henry's law), such that $C_{O 2, m(l)}=\left(C_{O 2, l}\right)_{r=R_{m}} / H_{O 2}$. Finally, microsensor measurements of concentration profiles of DO in water were used to determine the concentration gradient at the membrane surface, $\left(d C_{O 2, l} / d r\right)_{r=R m}$ and the concentration

$244\left(C_{O 2, l}\right)_{r=R_{m}}$. As mentioned above, profiles were collected at least in triplicate, and the 245 reported $K_{m}$ is the average of the replicates.

\subsection{Numerical model for gas back-diffusion}

248 A mathematical model for gas back-diffusion was developed, addressing both steadystate and transient conditions. The model included $\mathrm{O}_{2}$ supply from the HFM lumen, and assumed that the bulk liquid was in equilibrium with 1 atm of $\mathrm{N}_{2}$. The model was implemented with the finite-element simulation platform COMSOL Multiphysics (COMSOL 4.4, Comsol Inc., Burlington, MA, www.comsol.com).

The numerical model included fluid flow and mass transport of $\mathrm{O}_{2}$ and $\mathrm{N}_{2}$, both in the liquid surrounding the HFM and in the lumen gas (Figure 3). For the flow and mass transport in the liquid phase, a two-dimensional (2-D) axisymmetric geometry was set along the axis of the membrane lumen (direction $\mathrm{x}$ ) with radial gradients along direction r. The 2-D model implies an annular cross-section for the flow, with size $\mathrm{L}_{\mathrm{f}}=3.4 \mathrm{~mm}$ (the radius of a circle with the same area as the square cross-section). This model was coupled with a one-dimensional (1-D) domain for gas flow and mass transport in the membrane lumen (assuming no radial gradients in the lumen). 
(a)

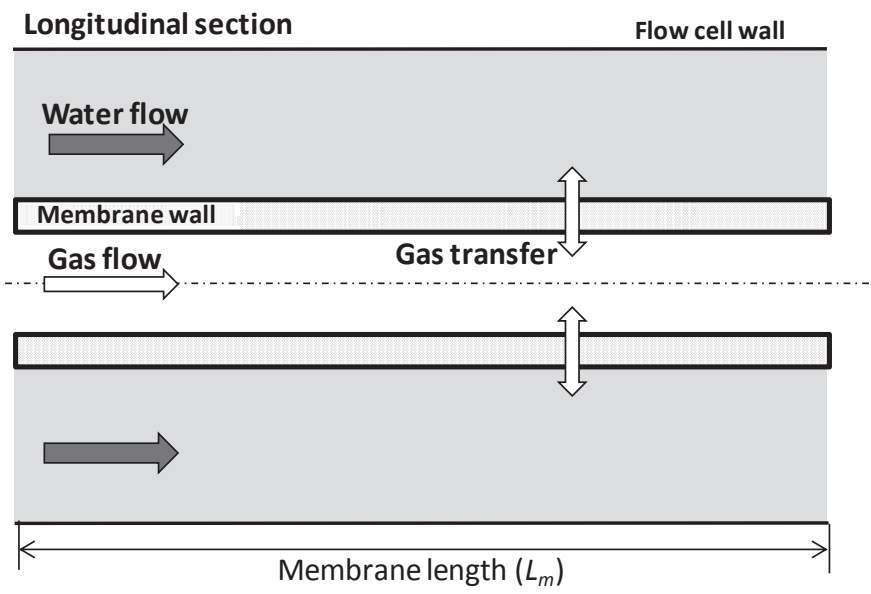

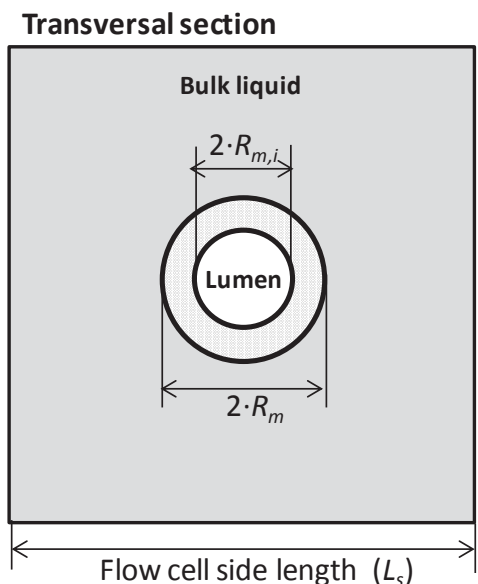

(b)

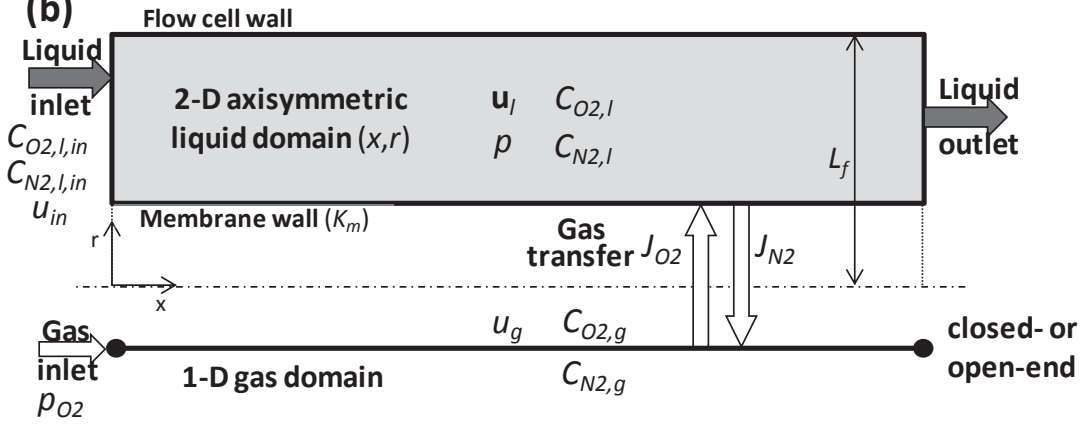

Figure 3. (a) Schematic representation (not at scale) of the experimental co-current aeration system with a single HFM inside a square-section flow cell filled with liquid. Water flows between the HFM and the flow cell wall, and the membrane is supplied with oxygen. (b) Model representation including a 2-D axisymmetric liquid domain connected via the membrane wall with a 1-D gas domain.

\subsubsection{Flow and mass transport in the liquid}

268 The liquid velocity distribution in the flow cell was determined by solution of the twodimensional Navier-Stokes equations (3) and (4) in the 2-D axisymmetric domain:

$$
\rho\left(\mathbf{u}_{l} \cdot \nabla\right) \mathbf{u}_{l}=\nabla \cdot\left[-p \mathbf{I}+\mu\left(\nabla \mathbf{u}_{l}+\left(\nabla \mathbf{u}_{l}\right)^{T}\right)\right], \quad \nabla \cdot \mathbf{u}_{l}=0
$$

271 where $\mathbf{u}_{l}$ is the water flow velocity, $p$ is the pressure, $\rho$ is the water density, $\mu$ is the

272 liquid dynamic viscosity, and $\mathbf{I}$ is the identity matrix. The water velocity was assumed to

273 be zero at the membrane surface and at the flow cell wall (non-slip condition, $\mathbf{u}_{l}=0$ ). 
274 Laminar flow conditions were imposed, with average velocity $u_{\text {in }}$ in the inlet and zero

275 relative pressure in the outlet.

276 The mass transport of oxygen and nitrogen in the liquid flow results from convection-

277 diffusion equations (5) and (6) solved for the dissolved $\mathrm{O}_{2}$ and $\mathrm{N}_{2}$ concentrations, $C_{O 2, l}$

278 and $C_{N 2, l}:$

279

$\mathbf{u}_{l} \nabla C_{O 2, l}=D_{O 2, l} \nabla^{2} C_{O 2, l}, \quad \mathbf{u}_{l} \nabla C_{N 2, l}=D_{N 2, l} \nabla^{2} C_{N 2, l}$

280

281

282

284

285

286

287

288

where $D_{O 2, l}$ and $D_{N 2, l}$ are the diffusion coefficients in the liquid. Constant dissolved $\mathrm{O}_{2}$ and $\mathrm{N}_{2}$ concentrations were imposed at the inlet boundary, $C_{O 2, l, i n}$ and $C_{N 2, l, i n} . \mathrm{N}_{2}$ was present in the feed water at $18 \mathrm{mg} / \mathrm{L}$, which corresponds to equilibrium with 1 atm of $\mathrm{N}_{2}$. Convection-only outlet boundary was assigned $\left(\partial C_{O 2, l} / \partial x=\partial C_{N 2, l} / \partial x=0\right)$, while no-flux conditions were imposed at the flow cell wall $\left(\partial C_{O 2, l} / \partial y=\partial C_{N 2, l} / \partial y=0\right)$. On the membrane wall, flux continuity conditions were set:

$$
J_{O 2}=K_{m}\left(C_{O 2, g} H_{O 2}-C_{O 2, l}\right), \quad J_{N 2}=K_{m}\left(C_{N 2, g} H_{N 2}-C_{N 2, l}\right)
$$

where $H_{O 2}$ and $H_{N 2}$ are the gas-liquid partition (Henry's) coefficients at $20{ }^{\circ} \mathrm{C}$. We assumed that the membrane, which was microporous, had the same selectivity for $\mathrm{O}_{2}$ and $\mathrm{N}_{2}$ (Ahmed and Semmens, 1992a), which translates to the same $K_{m}$.

\subsubsection{Flow and mass transport in the gas}

The mass balances for the gases in the membrane lumen were adapted from Ahmed and Semmens (1992a), who modeled steady-state $\mathrm{O}_{2}$ and $\mathrm{N}_{2}$ profiles in a closed-end HFM.

Unlike the past model, our model includes transient behavior, and used computational fluid dynamics to determine dissolved gas concentrations in the fluid along the 
membrane length. Frictional gas pressure losses in the lumen were included, and the model allowed for transient conditions to be simulated, for example when switching from open-end to closed-end operation. Finally, the membrane mass transfer resistance $\left(K_{m}\right)$ was considered explicitly. Note that only longitudinal gradients in gas concentrations (direction $x$ ) were considered in our model.

In both closed-end and open-end operation, the one-dimensional transient mass balances for $\mathrm{O}_{2}$ (eq.(7)) and $\mathrm{N}_{2}$ gas (eq.(8)) in the membrane lumen included transport by convection and diffusion, and transfer across the wall into or from the liquid phase.

These equations allowed the concentrations $C_{O 2, g}(t, x)$ and $C_{N 2, g}(t, x)$ to be calculated.

$\frac{\partial C_{O 2, g}}{\partial t}=\frac{\partial}{\partial x}\left(D_{g} \frac{\partial C_{O 2, g}}{\partial x}-u_{g} C_{O 2, g}\right)-\frac{2}{R_{m}} K_{m}\left(C_{O 2, g} H_{O 2}-C_{O 2, l}\right)$

$\frac{\partial C_{N 2, g}}{\partial t}=\frac{\partial}{\partial x}\left(D_{g} \frac{\partial C_{N 2, g}}{\partial x}-u_{g} C_{N 2, g}\right)-\frac{2}{R_{m}} K_{m}\left(C_{N 2, g} H_{N 2}-C_{N 2, l}\right)$

In eq. (7) and (8), $u_{g}$ is the gas velocity in the fiber, while $C_{O 2, l}$ and $C_{N 2, l}$ are the corresponding dissolved $\mathrm{O}_{2}$ and $\mathrm{N}_{2}$ concentrations, respectively, at position $x$. The same mass transfer coefficient through the membrane, $K_{m}$, and the same diffusion coefficient in the gas phase, $D_{g}$, was assumed for both gases.

The gas velocity in the lumen was calculated differently for close-end or open-end operation. In the closed-end operation, frictional losses were neglected due to the very low gas velocity in the lumen. For this case, the sum of gas concentrations at any point $x$ is equal to that of the inlet: $C_{O 2, g}+C_{N 2, g}=C_{O 2, i n}+C_{N 2, i n}=$ constant. In these conditions, the sum of eq. (7) and (8) is equal to zero. Adding eq. (7) and (8), and rearranging, results in: 
$317 \frac{d u_{g}}{d x}=-\frac{2 K_{m}\left(C_{O 2, g} H_{O 2}-C_{O 2, I}+C_{N 2, g} H_{N 2}-C_{N 2, l}\right)}{R_{m}\left(C_{O 2, \text { in }}+C_{N 2, i n}\right)}$

318 which allows for calculation of the local gas velocity along the fiber, $u_{g}(x)$, resulting 319 from the diffusion of gasses into or out of the membrane. At the sealed end, the gas 320 velocity must be zero $\left(u_{g}=0\right.$ at $\left.x=L_{m}\right)$. The inlet concentrations were calculated from the universal gas law, for example, $C_{O 2, g, i n}=p y_{O 2, i n} /(R T)$ with $y_{O 2, \text { in }}$ the oxygen fraction in the inlet gas (i.e., 1 for pure oxygen or 0.21 for air). In model simulations for the parametric study, only pure oxygen was used, i.e., $C_{N 2, g, i n}=0$.

324 For the open-end HFM, the constant gas velocity $u_{g}$ was calculated from the HagenPoiseuille relationship, which is valid for slightly compressible fluids (Federspiel et al., 1996):

$$
u_{g}=\frac{R_{m, i}^{2}}{8 \mu_{g} L_{m}}\left(p_{\text {in }}-p_{\text {out }}\right)
$$

where $\mu_{g}$ is the gas dynamic viscosity and $R_{m, i}$ is the internal fiber radius. The inlet pressure $p_{\text {in }}$ was defined according to the measured value, while the outlet pressure $p_{\text {out }}$ was set as atmospheric pressure.

The boundary conditions for equations (7) and (8) imply constant concentrations in the inlet $C_{O 2, g, \text { in }}$ and $C_{N 2, g, i n}$ at $x=0$. At $x=L_{m}$, zero diffusion was assumed for the open-end case, while for the closed-end zero total flux was imposed, which in both cases leads to:

$$
\frac{\partial C_{O 2, g}}{\partial x}\left(t, x=L_{m}\right)=0, \quad \frac{\partial C_{N 2, g}}{\partial x}\left(t, x=L_{m}\right)=0
$$

Initial gas concentrations for the entire membrane were equal to the inlet concentrations.

Predicted DO concentrations at the surface of the fiber $\left(C_{O 2, l}\right)$ were directly compared with experimental measurements for both steady and transient states. Several model 
parameters were taken from the experimental conditions, such as membrane thickness,

339 average water velocity, membrane length and radius, dissolved nitrogen, dissolved

340 oxygen in the influent water, and oxygen gas pressures in the membrane inlet and

341 outlet. For the model application, parametric studies were used, where simulations were

342 carried out for a range of values of a single parameter. These and other parameters

343 obtained from literature are summarized in Table 1.

344 Table 1. Model parameters

\begin{tabular}{|c|c|c|c|c|}
\hline Parameter & Symbol & Value & Units & Reference \\
\hline \multicolumn{5}{|l|}{ Physical parameters } \\
\hline Water density & $\rho$ & 1000 & $\mathrm{~kg} / \mathrm{m}^{3}$ & $\begin{array}{l}\text { (Haynes et al., } \\
\text { 2015) }\end{array}$ \\
\hline Water dynamic viscosity & $\mu$ & 0.001 & $\mathrm{~Pa} \cdot \mathrm{s}$ & $\begin{array}{l}\text { (Haynes et al., } \\
\text { 2015) }\end{array}$ \\
\hline Gas dynamic viscosity & $\mu_{g}$ & $1.8 \cdot 10^{-5}$ & $\mathrm{~Pa} \cdot \mathrm{s}$ & $\begin{array}{l}\text { (Haynes et al., } \\
\text { 2015) }\end{array}$ \\
\hline $\begin{array}{c}\mathrm{O}_{2} \text { diffusion coefficient in } \\
\text { water }\end{array}$ & $D_{O 2, l}$ & $2 \cdot 10^{-9}$ & $\mathrm{~m}^{2} / \mathrm{s}$ & $\begin{array}{l}\text { (Haynes et al., } \\
\text { 2015) }\end{array}$ \\
\hline $\begin{array}{c}\mathrm{N}_{2} \text { diffusion coefficient in } \\
\text { water }\end{array}$ & $D_{N 2, l}$ & $1.7 \cdot 10^{-9}$ & $\mathrm{~m}^{2} / \mathrm{s}$ & $\begin{array}{l}\text { (Haynes et al., } \\
\text { 2015) }\end{array}$ \\
\hline $\begin{array}{c}\mathrm{O}_{2} \text { and } \mathrm{N}_{2} \text { diffusivity in } \\
\text { gas }\end{array}$ & $D_{g}$ & $1.76 \cdot 10^{-5}$ & $\mathrm{~m}^{2} / \mathrm{s}$ & $\begin{array}{l}\text { (Haynes et al., } \\
\text { 2015) }\end{array}$ \\
\hline Henry coefficient for $\mathrm{O}_{2}$ & $H_{O 2}$ & 0.0338 & $\operatorname{mol}(\mathrm{aq}.) / \operatorname{mol}(\mathrm{g})$ & $\begin{array}{l}\text { (Haynes et al., } \\
\text { 2015) }\end{array}$ \\
\hline Henry coefficient for $\mathrm{N}_{2}$ & $H_{N 2}$ & 0.0156 & $\operatorname{mol}(\mathrm{aq}.) / \operatorname{mol}(\mathrm{g})$ & $\begin{array}{l}\text { (Haynes et al., } \\
\text { 2015) }\end{array}$ \\
\hline Ideal gas constant & $R$ & $8.206 \cdot 10^{-5}$ & $\mathrm{~m}^{3} \cdot \operatorname{atm} /(\mathrm{mol} \cdot \mathrm{K})$ & - \\
\hline \multicolumn{5}{|l|}{ Membrane parameters } \\
\hline Mass transfer coefficient & $K_{m}$ & $5.4 \cdot 10^{-5}$ & $\mathrm{~m} / \mathrm{s}$ & $\begin{array}{l}\text { Fitted to } \\
\text { experiments }\end{array}$ \\
\hline Length & $L_{m}$ & $\begin{array}{c}0.32 \\
2.5\end{array}$ & $\begin{array}{l}\mathrm{m} \\
\mathrm{m}\end{array}$ & $\begin{array}{c}\text { Experimental } \\
\text { Parametric study }\end{array}$ \\
\hline Outer radius & $R_{m}$ & 140 & $\mu \mathrm{m}$ & Mitsubishi Rayon \\
\hline Inner radius & $R_{m, i}$ & 130 & $\mu \mathrm{m}$ & Mitsubishi Rayon \\
\hline
\end{tabular}

Operation conditions

Oxygen inlet liquid concentration

$C_{O 2, l, i n}$

0

$\mathrm{mol} / \mathrm{m}^{3}$

Experimental 


\begin{tabular}{|c|c|c|c|c|}
\hline $\begin{array}{l}\text { Nitrogen inlet liquid } \\
\text { concentration }\end{array}$ & $C_{N 2, l, i n}$ & 0.64 & $\mathrm{~mol} / \mathrm{m}^{3}$ & Experimental \\
\hline $\begin{array}{l}\text { Oxygen inlet gas } \\
\text { concentration }\end{array}$ & $C_{O 2, g, \text { in }}$ & 69.7 & $\mathrm{~mol} / \mathrm{m}^{3}$ & Experimental \\
\hline $\begin{array}{l}\text { Nitrogen inlet gaseous } \\
\text { concentration }\end{array}$ & $C_{N 2, g, i n}$ & 0 & $\mathrm{~mol} / \mathrm{m}^{3}$ & Experimental \\
\hline Inlet gas pressure & $p_{\text {in }}$ & $\begin{array}{l}1.07 \text { and } 1.18 \\
1.68\end{array}$ & $\begin{array}{l}\mathrm{atm} \\
\mathrm{atm}\end{array}$ & $\begin{array}{c}\text { Experimental } \\
\text { Parametric study }\end{array}$ \\
\hline $\begin{array}{l}\text { Outlet gas pressure } \\
\text { (for open-end) }\end{array}$ & $p_{\text {out }}$ & 1 & atm & Experimental \\
\hline Average liquid velocity & $u_{\text {in }}$ & 1 and 5 & $\mathrm{~mm} / \mathrm{s}$ & Experimental \\
\hline Venting interval & $t_{c}$ & $\begin{array}{c}1,2,5,10 \text { and } \\
30\end{array}$ & $\min$ & Parametric study \\
\hline Venting open-end duration & $t_{o}$ & 20 & $\mathrm{~s}$ & Parametric study \\
\hline Temperature & $T$ & 293.15 & $\mathrm{~K}$ & Experimental \\
\hline
\end{tabular}

345

346

3. RESULTS AND DISCUSSION

\section{3.1 Determination of membrane mass transfer coefficient}

348 A typical plot of measured DO profiles, perpendicular to the membrane surface, is

349 shown in Figure 4. From the slope of the measured DO concentration profile, the flux of

350 oxygen was calculated with eq. (1). Subsequently, the mass transfer coefficient $K_{m}$ was

351 calculated from eq. (2). An average $K_{m}$ value of $5.4 \times 10^{-5} \mathrm{~m} / \mathrm{s}$ was obtained. This value

352 is consistent with previously determined oxygen mass transfer coefficients for the same

353 membrane (Ahmed et al., 2004) who found $K_{m}=5 \times 10^{-5} \mathrm{~m} / \mathrm{s}$. In this study, the mass transfer coefficients for $\mathrm{N}_{2}$ and $\mathrm{O}_{2}$ were assumed to be equal. 


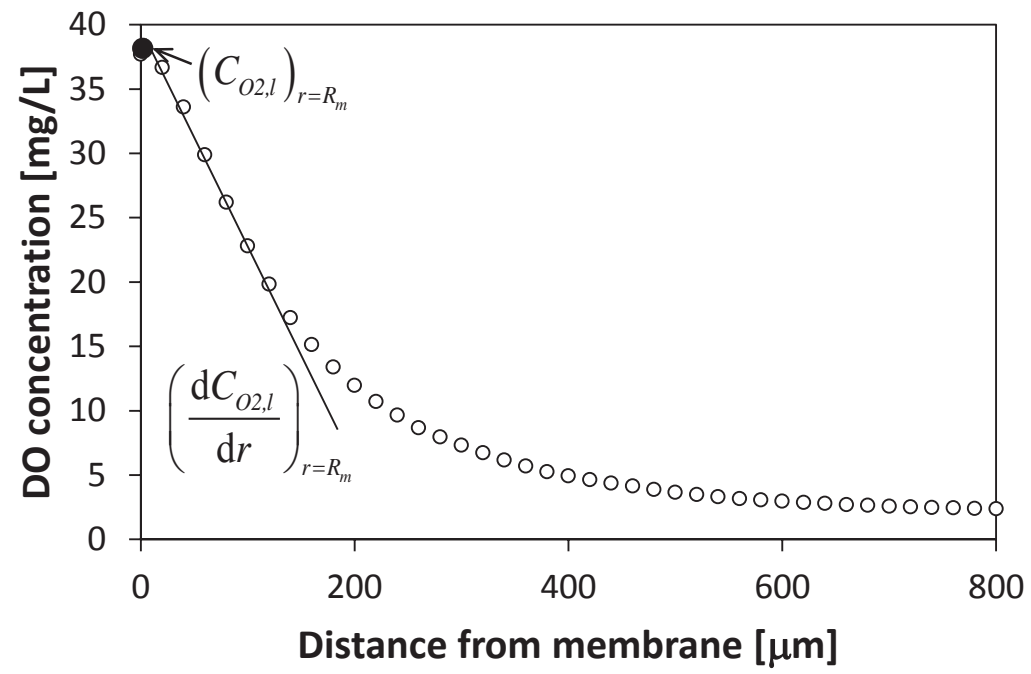

355

Figure 4. A representative profile of measured dissolved oxygen concentration through the mass transfer boundary layer in the liquid adjacent to the membrane. From this profile, the concentration and the normal gradient of concentration at the membrane surface ( $d=0$ from membrane, which means $r=R_{m}$ in the numerical model) were extracted to calculate $K_{m}$.

\subsection{Model evaluation}

The back-diffusion model results were in good agreement with the measured values of DO along the membrane length, both for open- and closed-end operation, in steady state and transient conditions (Figure 5).

For closed ends using either air or pure $\mathrm{O}_{2}$ supplied in co-current with the liquid flow $\left(u_{\text {in }}=5 \mathrm{~mm} / \mathrm{s}\right)$, the $\mathrm{N}_{2}$ back-diffusion significantly reduced the DO concentrations along the membrane length. The DO concentrations decreased from $35 \mathrm{mg} / \mathrm{L}$ to $5 \mathrm{mg} / \mathrm{L}$ when pure $\mathrm{O}_{2}$ was supplied, and from $6 \mathrm{mg} / \mathrm{L}$ to $0.5 \mathrm{mg} / \mathrm{L}$ in case of air (Figure $5 \mathrm{a}$ ). Accordingly, the steady state partial pressure of $\mathrm{O}_{2}$ in the membrane lumen significantly decreased as $\mathrm{O}_{2}$ was replaced by $\mathrm{N}_{2}$ (Figure $5 b$ ). However, for the open-end operation, $\mathrm{O}_{2}$ concentrations remained almost constant and at high values until the distal end of the membrane (Figure 5a). The open-end operation mode typically resulted in negligible 
373 back-diffusion effects. The partial pressure of $\mathrm{O}_{2}$ in the gas decreased only slightly

374 along the membrane because of the frictional pressure loss (Figure 5b).

375 The counter-current configuration showed lower DO concentrations towards the end of

376 the membrane than the co-current configuration, in stationary conditions at an average

377 water velocity of $u_{\text {in }}=1 \mathrm{~mm} / \mathrm{s}$ (Figure $5 \mathrm{c}$ ). When water flows in the opposite direction

378 of the supplied gas, i.e., in counter-current operation, $\mathrm{O}_{2}$ transferred to the bulk liquid

379 from the membrane does not accumulate downstream of the flow cell, thus decreasing

380 DO concentrations in the liquid towards the closed end of the membrane. Therefore, the

381 rest of the simulations considered only co-current operation. The partial pressure of $\mathrm{O}_{2}$

382 in the counter-current operation decreases more than in the co-current because of the

383 larger driving force for the trans-membrane transfer at the distal end, which is created

384 by the oxygen-free influent water.

385 The model also accurately predicted the transient behavior of the DO concentration after

386 suddenly closing the distal end of the membrane. The DO profile began with the steady

387 state value in open-end operation, and progressively decreased towards the steady state

388 value for the closed-end period. The experimental values and model predictions for the

389 Port 4 are shown in Figure 5e. The time required to reach a steady $\mathrm{O}_{2}$ profile in the lumen during the back-diffusion process was around 30 minutes. 

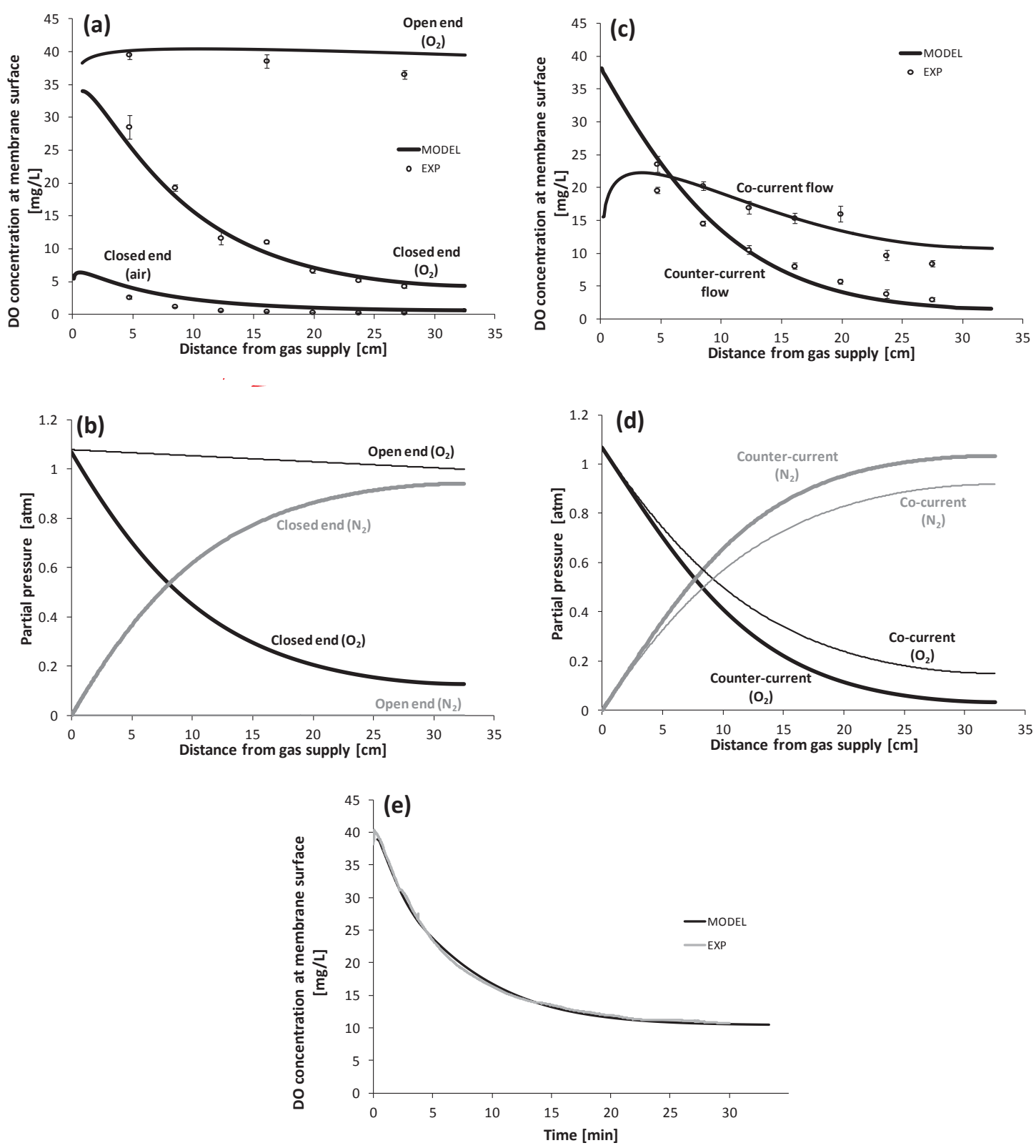

392 Figure 5. Experimental and model-simulated dissolved oxygen (DO) profiles at the membrane surface for the experimental HFM flow cell. Liquid and gas flows are co-current, unless indicated otherwise. (a) DO profiles for open and closed end operation modes using an inlet relative gas pressure of $0.18 \mathrm{~atm}$ and $u_{i n}=5 \mathrm{~mm} / \mathrm{s}$. DO profiles for air and oxygen as supply gases are shown for the closed end cases; (b) Simulations of partial pressures for $\mathrm{O}_{2}$ and $\mathrm{N}_{2}$ in the open-end and closed-end with pure $\mathrm{O}_{2}$ supply; (c) DO profiles along the membrane length for closed-end mode in co- and counter-current flow configurations using pure oxygen at 0.07 atm and $u_{i n}=1 \mathrm{~mm} / \mathrm{s}$; (d) Simulations of partial pressures for $\mathrm{O}_{2}$ and $\mathrm{N}_{2}$ in the closed-end co- and counter-current operation with pure $\mathrm{O}_{2}$ supply; (e) DO concentrations over time when transitioning from an open-end to a closed-end operation using pure $\mathrm{O}_{2}$ at an inlet pressure of $0.18 \mathrm{~atm}$. The microsensor measurement was performed at the membrane surface, for Port 4 at $16.1 \mathrm{~cm}$ from the inlet. Error bars in plots (a) and (c) are the standard deviation of triplicate measurements. 


\subsection{Model-based assessment of periodic venting}

406

407

408

409

410

411

412

413

414

415

416

417

418

419

420

421

422

Closed-end HFMs initially have high gas transfer rates, as the membranes are filled with pure $\mathrm{O}_{2}$. However, the rates quickly decrease as gas back-diffusion profiles develop. We used numerical modeling to study the effects of periodically venting closed-end membranes, temporarily returning the membranes to the initial condition by venting the back-diffusion gases. The transitory gas dynamics of periodic venting were studied, and the impacts of different membrane opening intervals on OTRs and OTEs were explored.

Time-averaged $\mathrm{O}_{2}$ partial pressures during three venting cycles were calculated from simulations with $R_{m}=140 \mu \mathrm{m}, K_{m}=5 \times 10^{-5} \mathrm{~m} / \mathrm{s}$, a longer membrane $\left(L_{m}=2.5 \mathrm{~m}\right)$ than in the experimental setup (closer to what might be used in a full-scale MABR) and an inlet gas pressure of $p_{i n}=1.68 \mathrm{~atm}$. Each cycle included a 30 -minute closed period followed by a 20 -second open (venting) period. This corresponds to a 30-minute "venting interval". Figure 6 shows how, during the first cycle from $t=0$ to $t=30 \mathrm{~min}$ (closed phase), a drop in the membrane-averaged $\mathrm{O}_{2}$ partial pressure developed due to backdiffusion. Before the steady-state back-diffusion condition was fully obtained, the membrane was opened for 20 seconds, allowing the $\mathrm{O}_{2}$ partial pressures along the membrane to recover their maximum value, which was slightly lower (1.54 atm) than the inlet gas pressure due to the pressure drop resulting from high gas velocities in open-end periods. The Hagen-Poiseuille relationship for slightly compressible fluids effectively predicted the observed flows for a broad range of pressures, ranging from 0.07 to $0.68 \mathrm{~atm}$ (data not shown).

This periodic venting provides high OTEs during most of the cycle duration, while maintaining higher time-averaged $\mathrm{O}_{2}$ partial pressures than closed-end membranes. 
These results indicate that a 20 -second open phase every 30 minutes was sufficient to

430 allow oxygen pressure to recover its maximum value (1.54 atm) before the next closed 431 phase. On the other hand, the membrane-averaged oxygen partial pressure dropped from 1.54 to $0.86 \mathrm{~atm}$ during the closed-end phase. On average, the membrane had a higher

$433 \mathrm{O}_{2}$ pressure than in the steady-state, closed-end operation. Therefore, it provided a 434 greater OTR than the purely closed-end mode.

435 To evaluate how the duration of the closed-end/open-end cycles influenced the OTRs 436 and OTEs, we simulated different venting intervals (i.e., time between openings) ranging from 1 to 30 minutes, with a constant venting (open end) duration of 20 seconds closed end. Furthermore, the OTE values (75-99\%) were comparable to the closed end $(100 \%)$, and dramatically higher than the open end mode $(0.5 \%)$.

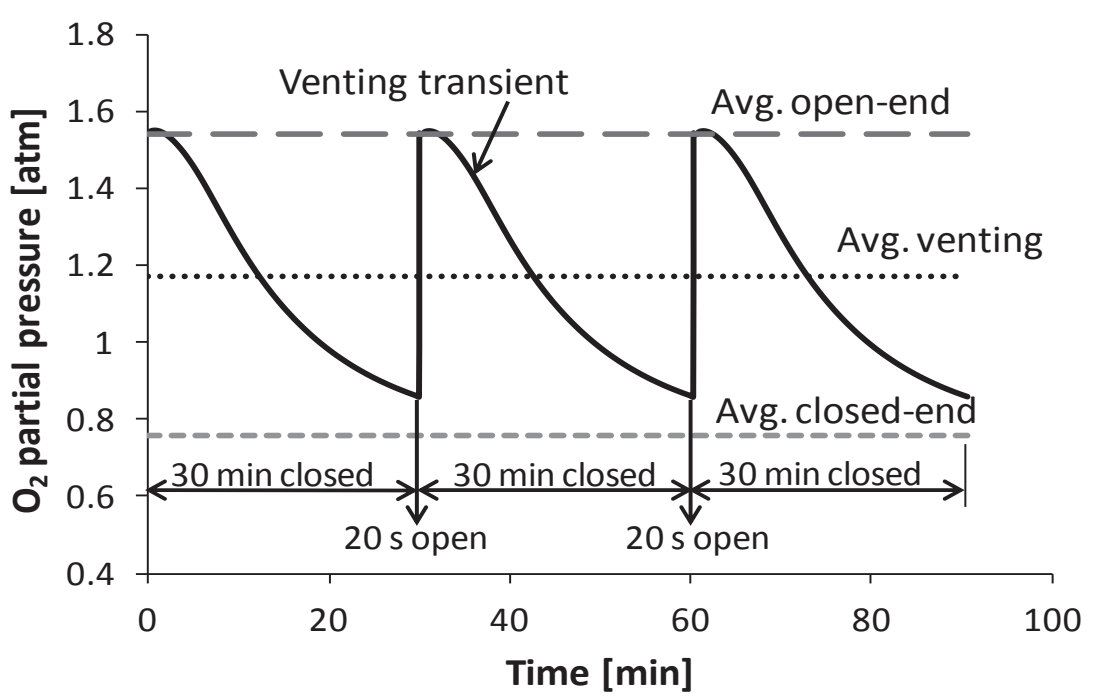

442 Figure 6. Simulated $\mathrm{O}_{2}$ partial pressures in the lumen, averaged along the entire membrane length for different operation regimes: (i) transient (solid line) and time-averaged (dotted line) during three venting cycles, (ii) steady state closed end (short-dashed gray line), and (iii) steady state open end (long-dashed gray line). 

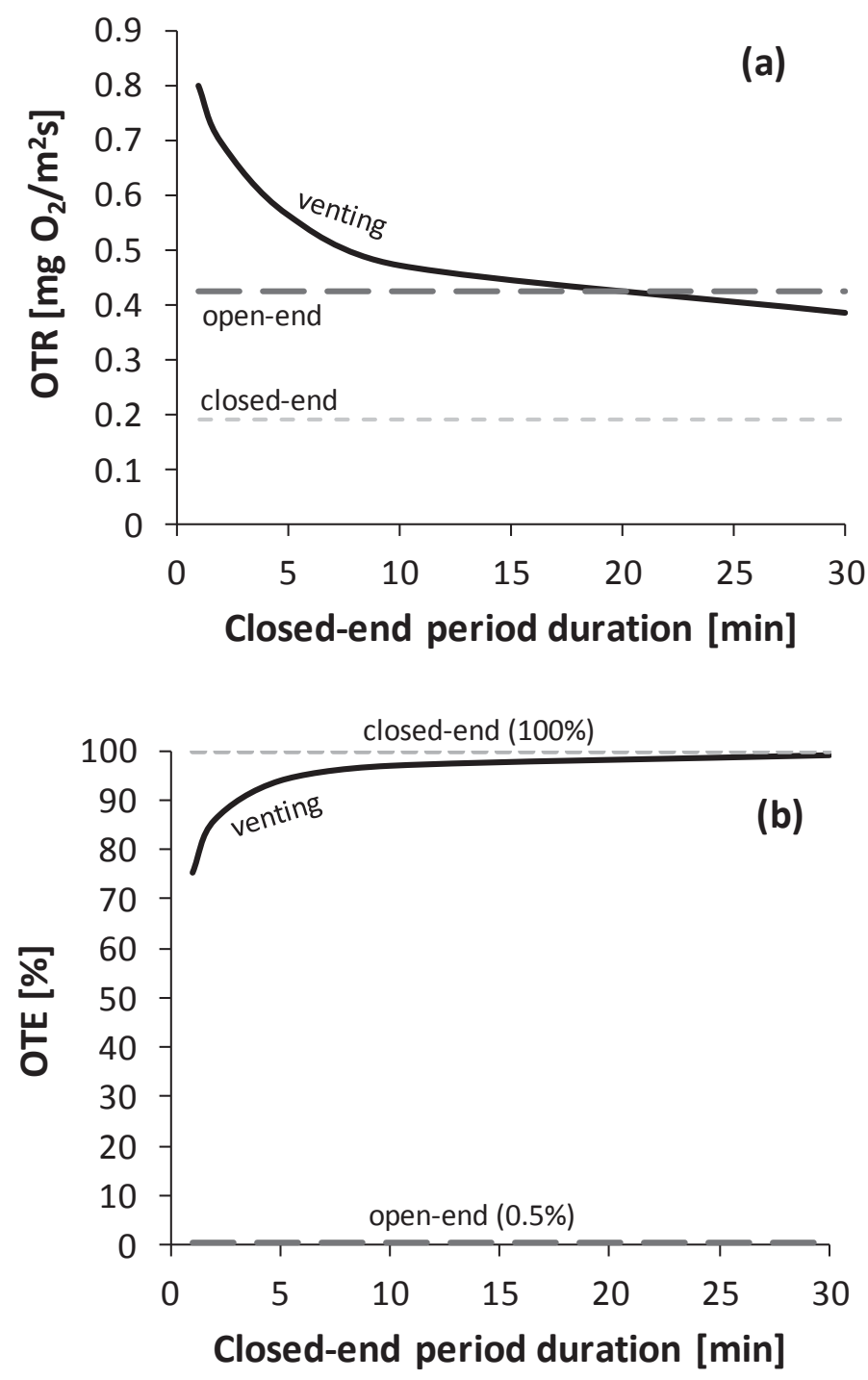

447 Figure 7. Comparison of simulated (a) oxygen transfer rates (OTR) and (b) oxyge transfer efficiencies 448 (OTE) for open operation, closed operation, and intermittent opening. Venting mode was tested for 449 venting intervals (time between ventings) ranging from 1 to $30 \mathrm{~min}$, with 20 seconds open phases.

451 Interestingly, when the venting interval decreased below approximately $20 \mathrm{~min}$, the 452 OTR values were higher than for purely open-end operation, without significantly 453 affecting the OTEs. This can be explained by the simulated $\mathrm{O}_{2}$ pressure profiles along 454 an HFM for open-end steady-state conditions, closed-end steady state conditions, and 455 for the transition from open-end to closed-ended conditions (Fig 8). Profiles for the 456 transition phase are presented at different times. For open-end operation, the $\mathrm{O}_{2}$ pressure 457 decrease is mainly due to frictional losses, whereas in closed-end operation the $\mathrm{O}_{2}$ 
458 pressure drop is caused by back-diffusion. Furthermore, for the closed-end case, the $\mathrm{O}_{2}$

459 concentration decreases from a constant initial value (equal to the inlet pressure of 1.68

460 atm), along the whole membrane until the steady state profile is reached. The shape of

461 the transient profiles shows that, initially, $\mathrm{N}_{2}$ back-diffusion only affects the initial

462 portion of the HFM. This is where pure $\mathrm{O}_{2}$ is supplied, and also where $\mathrm{O}_{2}$-free water

463 enters the system, providing the maximum $\mathrm{O}_{2}$ and $\mathrm{N}_{2}$ concentration gradients. Then the

$464 \mathrm{~N}_{2} / \mathrm{O}_{2}$ gas mixture is transferred by advective flow towards the distal end of the 465 membrane.

466 The time-dependent reduction in the $\mathrm{O}_{2}$ pressure profiles occurs during the closed phase 467 of a venting cycle. If the venting interval is smaller, the time- and length-averaged $\mathrm{O}_{2}$

468 pressure concentrations increase, leading to higher OTRs. However, below a certain 469 venting interval, the OTRs actually exceed those of the open-end configuration. This is 470 caused by the pressure drop resulting from high gas velocities in open-end 471 configuration. However, the pressure losses are negligible once the membrane is closed,

472 thus allowing a higher total average pressure inside the membrane (see pressure profiles 473 at times $t_{0}, t_{1}$, and $t_{2}$ in Figure 8).

474 The model results clearly indicate that periodic venting of closed-end operation can 475 improve the gas transfer rates beyond those obtainable with conventional open-end 476 operation, while maintaining high mass transfer efficiencies. 


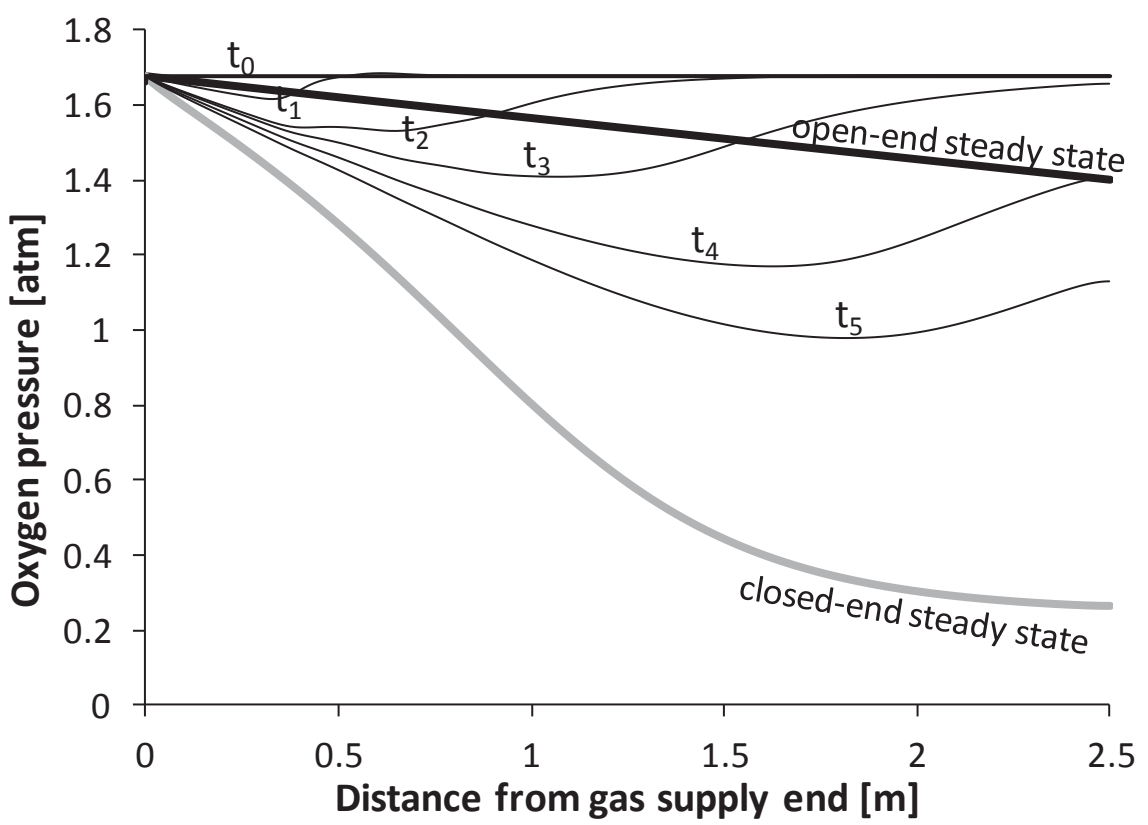

Figure 8. Oxygen partial pressure profiles along the membrane length for open-end (thick black line) and closed-end (thick gray line) steady state conditions, and time-averaged for transient conditions from opento closed-end (thin black lines). The transient pressures are averages in time between the initial time and $t_{1}=2 \mathrm{~min}, t_{2}=5 \mathrm{~min}, t_{3}=10 \mathrm{~min}, t_{4}=20 \mathrm{~min}$, and $t_{5}=30 \mathrm{~min}$. Steady state conditions were essentially achieved after 60 minutes.

A simple calculation was made to compare different gas supply modes and show how the venting strategy could impact the MABR design, such as membrane area and required oxygen supply. Table 2 shows the OTRs, OTEs, required membrane areas, and $\mathrm{O}_{2}$ supply needs using simulation results for the conditions in Figure 7. The membrane area was calculated for an arbitrary $\mathrm{O}_{2}$ requirement. Oxygen supply requirements were determined by multiplying the OTE by the $\mathrm{O}_{2}$ need. Finally, membrane areas and $\mathrm{O}_{2}$ supply requirements for open-end and venting modes were normalized to the values for closed-end operation (first row in Table 2). Calculations indicate that the open-end operation requires only half of the membrane area of the closed-end operation. However, around 200 times more $\mathrm{O}_{2}$ is required. With the intermittent venting of 20 seconds every 30 minutes, the required membrane area is the same as the open end, i.e., half of the area required for the closed-end operation. But $\mathrm{O}_{2}$ requirement is essentially the same as the closed-end operation. 
Table 2. Required membrane areas and oxygen fluxes for closed-end, open-end, and venting modes.

497 Areas and fluxes are normalized by the closed-end value.

\begin{tabular}{ccccc}
\hline Case & $\begin{array}{c}\text { OTR } \\
\left(\mathbf{m g ~ m}^{-2} \mathbf{s}^{-\mathbf{1}}\right)\end{array}$ & $\begin{array}{c}\text { OTE } \\
\mathbf{( \% )}\end{array}$ & $\begin{array}{c}\text { Normalized required } \\
\text { membrane area }\end{array}$ & $\begin{array}{c}\text { Normalized } \mathbf{O}_{2} \\
\text { supply requirement }\end{array}$ \\
\hline Closed end & 0.19 & 100 & 1.0 & 1.0 \\
Open end & 0.42 & 0.47 & 0.5 & 213 \\
$\begin{array}{c}\text { Venting } \\
\left(t_{c}=1 \text { min, }\right.\end{array}$ & 0.79 & 75.3 & 0.2 & 1.3 \\
$\begin{array}{c}\left.t_{0}=20 \mathrm{~s}\right) \\
\text { Venting } \\
\left(\begin{array}{c}t_{c}=30 \mathrm{~min}, \\
\left.t_{0}=20 \mathrm{~s}\right)\end{array}\right.\end{array}$ & 0.38 & 98.9 & 0.5 & 1.0 \\
\hline
\end{tabular}

498

499

500

3.4 Experimental assessment of gas supply strategies on HFMs with biofilm

501 The periodic venting strategy was tested in a bench-scale MABR treating COD. Figure

5029 shows the biofilm thicknesses and measured DO concentration profiles along the 503 membrane surface in two MABRs that were run in parallel. MABR-1 was operated in 504 open-end mode, and MABR-2 was operated in closed-end mode. Biofilm thickness images and measurements of DO profiles were taken after four weeks of operation. 
a) Open-end MABR-1

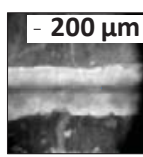

Port 1

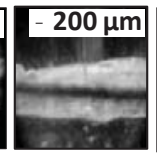

Port 3

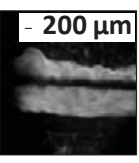

Port 5

Open-end MABR-1

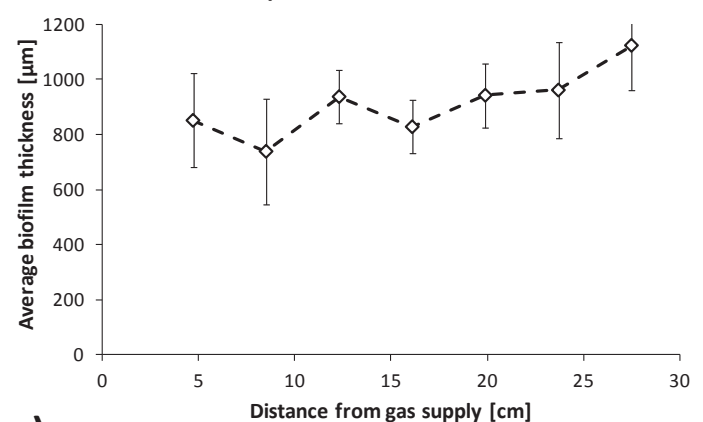

c)

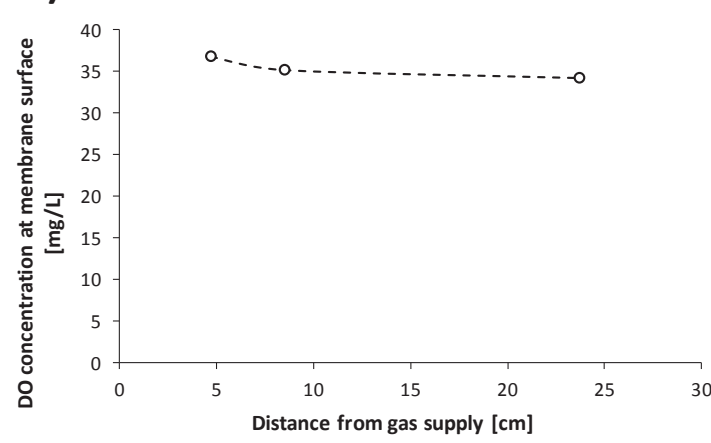

b) Closed-end MABR-2

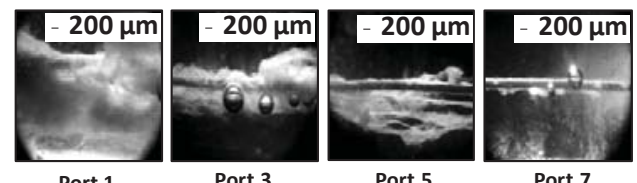

Closed-end MABR-2

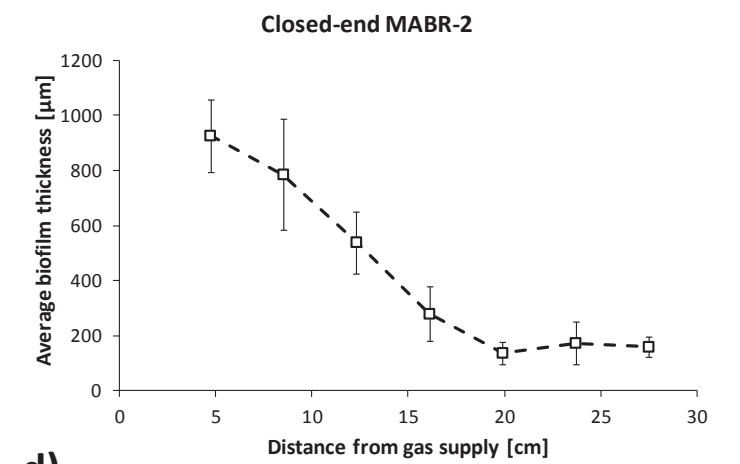

d)
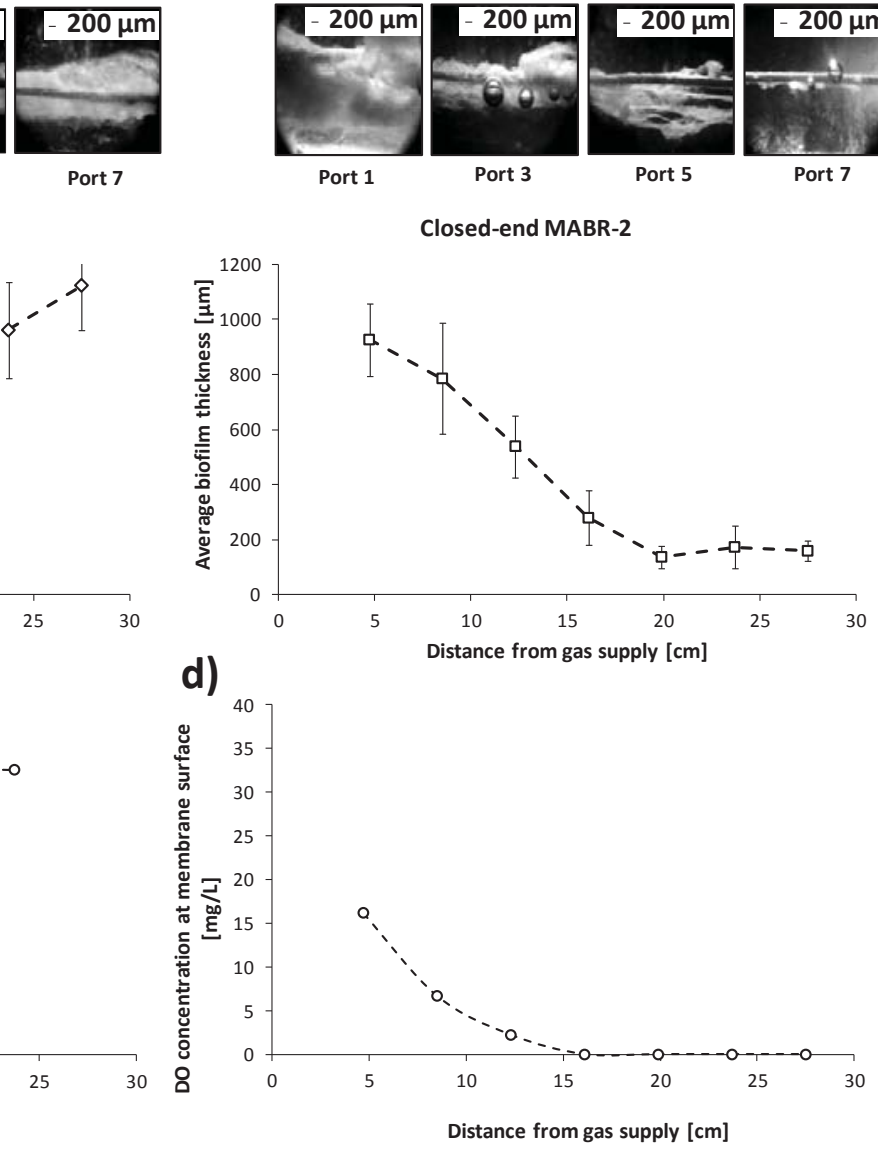

$$
\text { (1) }
$$

Distance from gas supply $[\mathrm{cm}]$

507 Figure 9. Biofilm thickness development along the membrane length in normally operated open-end 508 MABR-1 (a) and closed-end MABR-2 (b). Experimental DO profiles at membrane surface for open-end 509 MABR-1 (c) and closed-end MABR-2 (d). Port 1 is 4.7-cm from gas supply (left side), and Ports 3, 5, and $510 \quad 7$ are at $7.6-\mathrm{cm}$ increments from Port 1.

511 In MABR-1 (open end), a homogeneous biofilm grew through the fiber surface, with a 512 similar thickness along the membrane length (Figure 9a). In MABR-2 (closed end), the 513 biofilm was thick at the gas supply end, but was significantly reduced towards the 514 sealed end of the membrane (Figure 9 b). This can be explained by the measured DO 515 profiles along the membrane (Figure $9 \mathrm{c}$ and d). For MABR-1, the $\mathrm{O}_{2}$ concentrations 516 remained almost constant and at high values across the entire membrane (Figure $9 \mathrm{c}$ ).

517 This is because the high supply gas rate into the membrane resulted in negligible back-

518 diffusion effects. The partial pressure of $\mathrm{O}_{2}$ in the gas decreased only slightly along the 519 membrane because of frictional pressure loss. $\mathrm{N}_{2}$ accumulation in the membrane was 


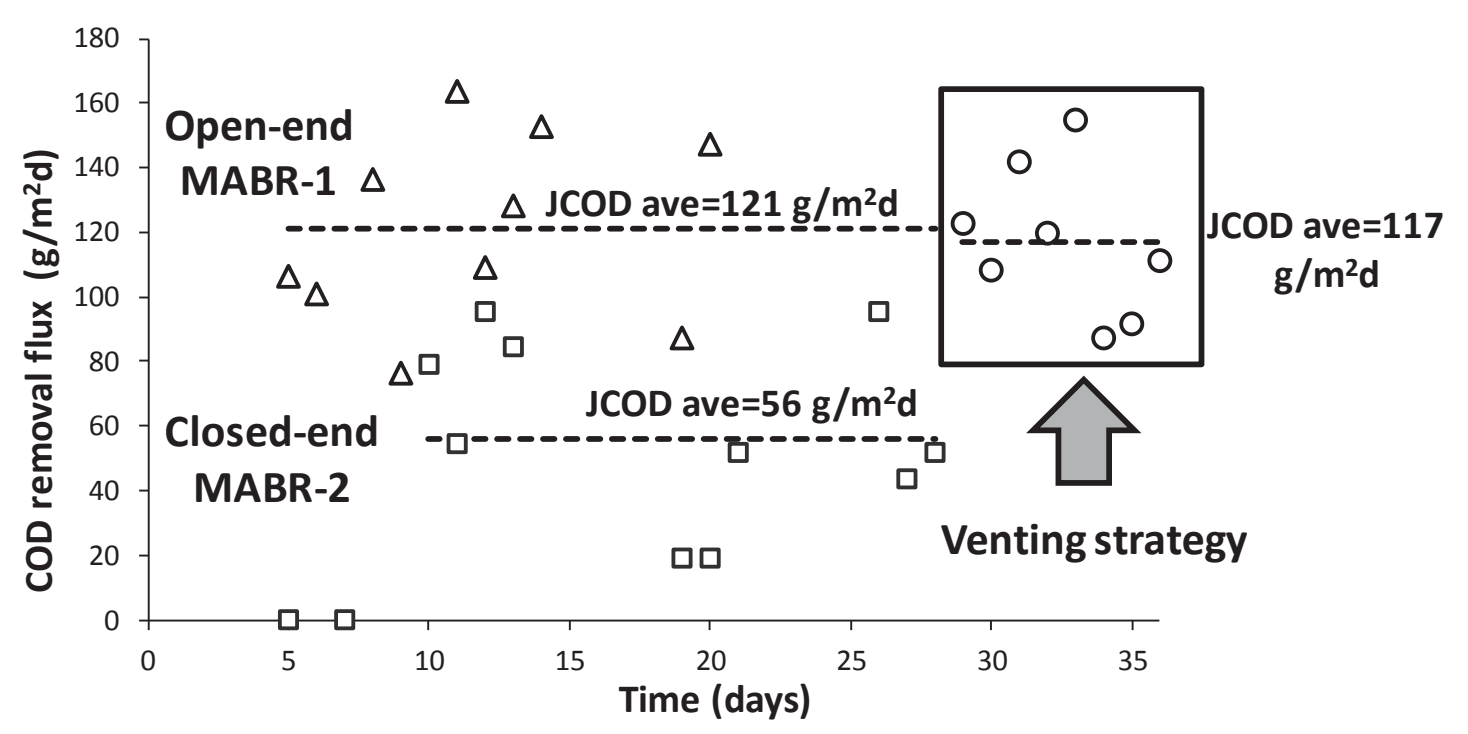

525

526

527

528

529

530

531

Figure 10: Experimentally observed COD removal fluxes in MABR-1 (triangles) and MABR-2 (squares) plotted against time. Circles enclosed in the black rectangle represent COD removal fluxes for the closedend MABR-2 when a venting strategy of 20 s open and 20 min closed was implemented.

The open-end MABR-1 had a higher average $\mathrm{O}_{2}$ pressure than in the steady-state, closed-end MABR-2 (Figure $9 \mathrm{c}$ and d). Therefore, it provided a greater OTRs and COD removal fluxes than the purely closed-end MABR-2 (Figure 10). The average COD removal flux for MABR-1 was double the value for MABR-2. In MABR-2, backdiffusion caused DO limitation in much of the membrane. This slowed the development of the biofilm, and consequently the increase in COD removal. Also, COD removal rates fluctuated considerably because this was a small reactor. As the biofilms grew, any biofilm detachment had a significant impact on the system. This would be more likely to average out in a larger system. 
538 Note that the predicted OTR values for closed, open and venting strategies in a clean

539 membrane were lower than those for MABRs. This is because the biofilm can eliminate

540 the mass transfer resistance of the liquid concentration boundary layer (Semmens 2008).

541 After four weeks of operation, MABR-2 was switched to periodic venting, which

542 consisted of opening the membrane (venting) for 20 seconds every 20 minutes. Figure

54310 shows the experimental COD removal fluxes that were obtained when periodic

544 venting cycles were applied to MABR-2. Figure 11 shows the biofilm thicknesses

545 along the membrane length prior to venting, and after eight days of venting cycles.

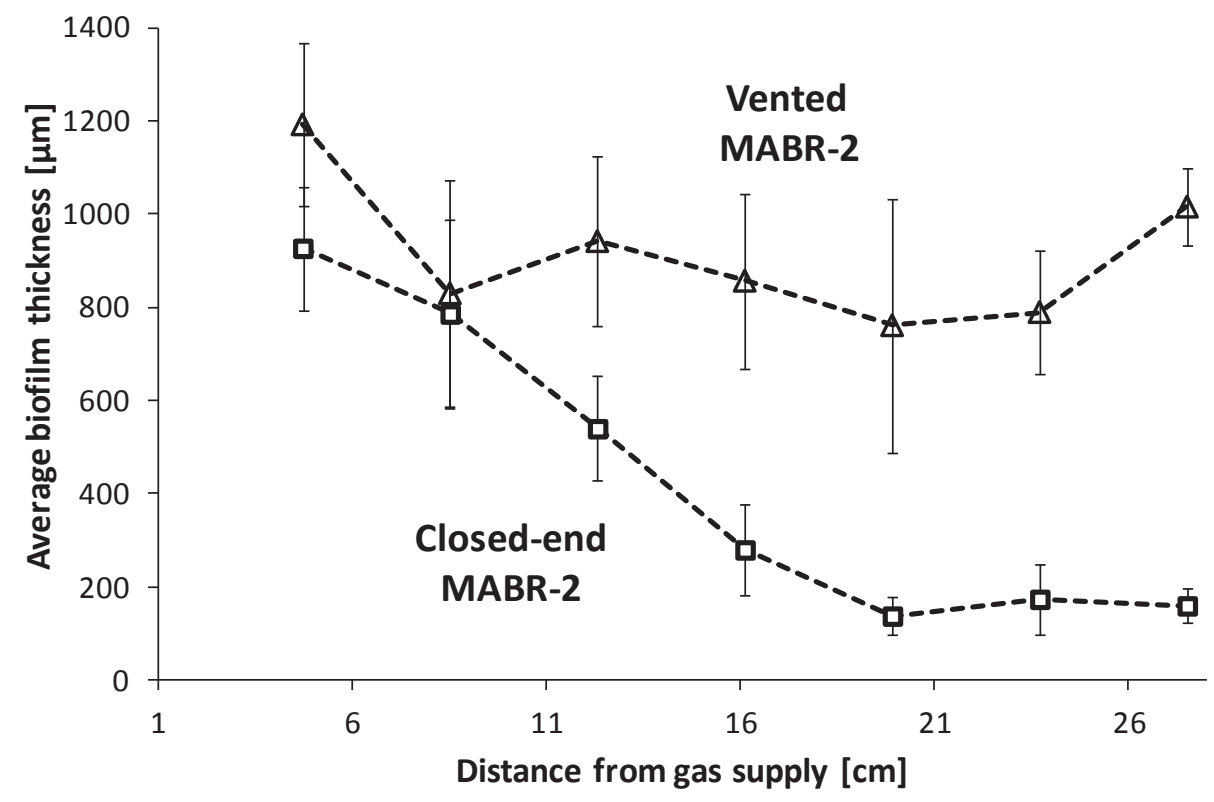

546

547 Figure 11. Biofilm thicknesses along the fiber length of MABR-2 just prior to initiating the venting 548 cycles, and after eight days of periodic venting. Venting provides a much more uniform biofilm thickness.

549 The mathematical model predicted that greater average $\mathrm{O}_{2}$ partial pressures, and 550 consequently higher OTRs and removal fluxes, could be obtained by applying periodic 551 venting to a closed-end MABR. The experimental COD removal fluxes are shown in 552 Figure 10. The average COD removal flux became double that for the closed-end 553 operation, increasing from $56 \mathrm{gCOD} / \mathrm{m}^{2} \mathrm{~d}$ to $117 \mathrm{gCOD} / \mathrm{m}^{2} \mathrm{~d}$. This value is very similar 554 to the $121 \mathrm{gCOD} / \mathrm{m}^{2} \mathrm{~d}$ obtained in MABR-1 (Figure 10). This was in part due to the 
555

556

557

558

559

560

561

562

563

564

565

566

567

568

569

570

571

572

573

574

575

576

577

578

more uniform biofilm thickness along the length of the fiber when periodic venting was implemented (Figure 11). Based on the measured gas flow rate through the membrane during the open cycles, OTEs of at least 97\% were obtained when applying the periodic venting. In this research, the COD removal rates were greater than those obtained in some previous MABR studies. This was mainly because we used pure oxygen as the supplied gas. Also, we used acetate as organic carbon source. Acetate is readily biodegradable substrate, as opposed to more complex organics such as wastewater. Nevertheless, COD removal rates found in this study were similar than the ones obtained by Osa et al. (1997), Pankhania et al. (1999) and Brindle et al. (1999), who reported COD removal rate values in MABRs fed with pure $\mathrm{O}_{2}$ of $180,42.7,62.6$ $\mathrm{gCOD} / \mathrm{m}^{2} \mathrm{~d}$ respectively. Experimental results verified that periodic venting of closedend MABRs can lead to high OTRs and OTEs, improving the overall process performance and increasing the energy efficiency.

This work highlights the potential transient behavior of gas back-diffusion, and the potentially significant lag in reaching steady state operation after a perturbation. For example, changing the supply gas pressure, concentration of supply gas in the liquid phase, and concentration of back-diffusion gases in the liquid phase, among others. Following any of these changes, it may take a considerable amount of time to reach steady state.

The optimal venting interval (time between openings) and venting time (open period) depends on a variety of factors, including the membrane mass transfer coefficient, diameter, length, supply gas pressure and concentration, and dissolved gas concentrations in the liquid. For instance, larger membrane diameters will likely allow a greater venting interval, as there is greater gas storage in the membrane lumen relative 
579

580

581

582

583

584

585

586

587

588

589

590

591

592

593

594

595

596

597

598

599

600

601

to the gas transfer across the membrane. Larger HFM diameters, and longer membrane lengths, would require longer venting periods. When selective membranes are used, the relationship between the diffusion coefficients can also be important. Finally, the effect of liquid flow in a contactor, e.g., co-current, counter-current, or cross flow, can impact the gas transfer rates and the transition to steady-state conditions. Future research should explore the impact of the above factors in more detail.

Past research on MABRs has shown that water vapor can diffuse into the membrane and condense at the sealed end, plugging part of the membrane (Côte et al., 1988; Côte et al., 1989., Fang et al., 2004). However, it would take weeks or months for condensation to have an appreciable effect on the membrane behavior. In our closed-end experiments, the membranes were vented every two days, and no sign of condensate accumulation was observed during the ventings. Some MABRs are periodically vented to remove water condensation, but the frequency of venting is typically too low to obtain the gas transfer rate benefits. Based on our findings, it would be easy to increase the venting frequency to both remove condensate and obtain higher OTRs.

The above strategy was studied for $\mathrm{O}_{2}$ supply to an MABR, but the periodic venting is also relevant to MABRs supplied with air, or MBfR applications with gases such as hydrogen gas $\left(\mathrm{H}_{2}\right)$ or methane $\left(\mathrm{CH}_{4}\right)$ (Martin and Nerenberg, 2012; Shi et al, 2013).

\section{CONCLUSIONS}

The periodic venting of lumen gases in a closed-end MABR can greatly improve the membrane's OTRs and contaminant removal fluxes, without significantly impacting the OTEs. This is due to the transient behavior of the lumen gas profiles when shifting 
602 from open-end to closed-end operation. When the venting interval is short enough, the

603 OTR can be even higher than with continuous open-end operation. This novel gas

604 supply strategy can greatly increase the capacity of MABRs, and decrease the capital

605 and operating cost of new systems. Future research should address in more detail the

606 range of factors that affect the selection of opening interval, the closed duration, and the

607 impacts of these factors on the OTRs and OTEs.

\section{ACKNOWLEDGEMENTS}

609 Primary funding for this work was from Water Environment Research Foundation

610 (WERF) project U2R14. Additional funding was provided by the Basque Government, 611 partially financing Patricia Pérez, and the Spanish Ministry of Economics and 612 Competitiveness and the European Regional Development Fund (FEDER), project “Innovative Integrated Biological Processes for Nutrients Removal (PBi2)" (CTM201236227).

\section{REFERENCES}

Ahmed, T., Semmens, M.J., 1992a. The Use of Independently Sealed Microporous Hollow Fiber Membranes for Oxygenation of Water - Model Development. Journal of Membrane Science 69(1-2), 1120. Ahmed, T., Semmens, M.J., 1992b. Use of Sealed End Hollow Fibers for Bubbleless Membrane Aeration - Experimental Studies. Journal of Membrane Science 69(1-2), 1-10.

Ahmed, T., Semmens, M.J., Voss, M.A., 2004. Oxygen transfer characteristics of hollow-fiber, composite membranes. Advances in Environmental Research 8, 637-646.

Aybar, M., Pizarro, G., Boltz, J.P., Downing, L., Nerenberg, R., 2014. Energy-efficient wastewater treatment via the air-based, hybrid membrane biofilm reactor (hybrid MfBR). Water Science and Technology 69(8), 1735-1741.

Brindle, K., Stephenson, T., Semmens, M.J., 1998. Nitrification and oxygen utilisation in a membrane aeration bioreactor. Journal of Membrane Science 144, 197-209.

Brindle, K., Stephenson,T., Semmens,M.J., 1999. Pilot-plant treatment of a high-strength brewery wastewater using a membraneaeration bioreactor. Water Environment Research. 71 (6), 1197- 1204. Castagna, L., Zanella, A., Scaravilli, V., Magni, F., Deab, S.A.E., Introna, M., Mojoli, F., Grasselli, G., Pesenti, A., Patroniti, N., 2015. Effects on membrane lung gas exchange of an intermittent high gas flow recruitment maneuver: preliminary data in veno-venous ECMO patients. Journal of Artificial Organs $18(3), 213-219$. 
Côte, P., Bersillon, J.L., Huyard, A., 1989. Bubble-Free Aeration Using Membranes - Mass-Transfer Analysis. Journal of Membrane Science 47(1-2), 91-106.

Côte, P., Bersillon, J.L., Huyard, A., Faup, G., 1988. Bubble-Free Aeration Using Membranes - Process Analysis. Journal Water Pollution Control Federation 60(11), 1986-1992.

Downing, L.S., Nerenberg, R., 2008. Total nitrogen removal in a hybrid, membrane-aerated activated sludge process. Water Research 42(14), 3697-3708.

Fang, Y., Clapp, L.W., Hozalski, R.M., Novak, P.J., Semmens, M.J., 2004. Membrane gas transfer under conditions of creeping flow: modeling gas composition effects. Water Research 38(10), 2489-2498. Federspiel, W.J., Henchir, K.A., 2004. Encyclopedia of Biomaterials and Biomedical Engineering, Marcel Dekker, Inc., Pittsburgh, PA.

Federspiel, W.J., Williams, J.L., Hattler, B.G., 1996. Gas flow dynamics in hollow-fiber membranes. Aiche Journal 42(7), 2094-2099.

Haynes, W.M., Bruno, T.J., Lide, D.R. (Ed.), 2015. CRC handbook of chemistry and physics CRC. Press/Taylor and Francis, Boca Raton, FL. Online at http://www.hbcpnetbase.com/ Hibiya, K.,. Terada, A., Tsuneda, S., Hirata, A., 2003. Simultaneous nitrification and denitrification by controlling vertical and horizontal microenvironment in a membrane-aerated biofilm reactor. Journal of Biotechnology 100(1), 23-32.

Hondzo, M., Feyaerts, T., Donovan, R., and O’Connor, B.L. 2005. Universal scaling of dissolved oxygen distribution at the sediment-water interface: A power law. Limnology and Oceanography 50, 1667-1676. Jácome, A., Molina, J., Suárez, J., Tejero, I., 2006. Simultaneous Removal of Organic Matter and Nitrogen Compounds in Autoaerated Biofilms. Journal of Environmental Engineering 132(10), 1255 1263.

Martin, K.J., Nerenberg, R., 2012. The membrane biofilm reactor (MBfR) for water and wastewater treatment: principles, applications, and recent developments. Bioresource Technology 122, 83-94. Matsuda, N., Nakamura, M., Sakai, K., Kuwana, K., Tahara, K., 1999. Theoretical and experimental evaluation for blood pressure drop and oxygen transfer rate in outside blood plow membrane oxygenator. Journal of Chemical Engineering of Japan 32(6), 752-759.

Matsumoto, S., Terada, A., Aoi, Y., Tsuneda, S., Alpkvist, E., Picioreanu, C., van Loosdrecht, M.C.M., 2007. Experimental and simulation analysis of community structure of nitrifying bacteria in a membraneaerated biofilm. Water Science and Technology 55(8-9), 283-290.

Nerenberg, R., 2016. The membrane-biofilm reactor (MBfR) as a counter-diffusional biofilm process. Current Opinion in Biotechnology 38, 131-136.

Osa, J., Eguia, E., Vidart, T., Jácome, A., Lorda, I., Amieva, J., Tejero, I., 1997. Wastewater Treatment with biofilm Membrane Reactors. In Conference on Advanced Wastewater Treatment Processes; Leeds University: Leeds, UK, 1997.

Pankhania, M., Brindle, K., Stephenson, T., 1999. Membrane aeration bioreactors for wastewater treatment: completely mixed and plug-flow operation. Chemical Engineering Journal 73(2), 131-136. Roggy, D.K., Novak, P.J., Hozalski, R.M., Clapp, L.W., Semmens, M.J., 2002. Membrane gas transfer for groundwater remediation: Chemical and biological fouling. Environmental Engineering Science 19(6), 563-574.

Satoh, H., Ono, H., Rulin, B., Kamo, J., Okabe, S., Fukushi, K., 2004. Macroscale and microscale analyses of nitrification and denitrification in biofilms attached on membrane aerated biofilm reactors. Water Research 38(6), 1633-1641.

Schaffer, R.B., Ludzack, F.J., Ettinger, M.B.C.F.p.d.S., 1960. Sewage Treatment by Oxygenation through Permeable Plastic Films. Journal (Water Pollution Control Federation) 32(9), 939-941.

Semmens, M.J., 2008. Alternative MBR configurations: using membranes for gas transfer. Desalination 231(1), 236-242.

Semmens, M.J., Dahm, K., Shanahan, J., Christianson, A., 2003. COD and nitrogen removal by biofilms growing on gas permeable membranes. Water Research 37(18), 4343-4350.

Shi Y, Hu S, Lou J, Lu P, Keller J, Yuan Z (2103). Nitrogen removal from wastewater by coupling anammox and methane-dependent denitrification in a membrane biofilm reactor. Environ Sci Technol 2013, 47:11577-11583.

Syron, E., Casey, E., 2008. Membrane-aerated biofilms for high rate biotreatment: performance appraisal, engineering principles, scale-up, and development requirements. Environmental Science and Technology 42(6), 1833-1844.

Tanishita, K., Nakano, K., Sakurai, Y., Hosokawa, T., Richardson, P.D., Galletti, P.M., 1978. Compact Oxygenator Design with Curved Tubes Wound in Weaving Patterns. Transactions American Society for Artificial Internal Organs 24, 327-331. 
Terada, A., Hibiya, K., Nagai, J., Tsuneda, S.,Hirata, A., 2003. Nitrogen removal characteristics and biofilm analysis of a membrane-aerated biofilm reactor applicable to high-strength nitrogenous wastewater treatment. Journal of Bioscience and Bioengineering 95(2), 170-178. Timberlake, D.L., Strand, S.E., Williamson, K.J., 1988. Combined aerobic heterotrophic oxidation, nitrification and denitrification in a permeable-support biofilm. Water Research 22(12), 1513-1517. Weiss, P.T., Gulliver, J.S., Semmens, M.J., 1998. In-stream hollow-fiber membrane aeration. Journal of Hydraulic Engineering 124(6), 579-588. Weissman, M.H., Mockros, L.F., 1969. Oxygen and Carbon Dioxide Transfer in Membrane Oxygenators. Medical \& Biological Engineering 7(2), 169-184. 